\title{
Global evidence of extreme intuitive moral prejudice against atheists
}

\author{
Gervais, Will M.
}

2017-08-07

Gervais , W M , Xygalatas , D , McKay , R T, van Elk, M , Buchtel , E E , Aveyard , M , Schiavone , S R , Dar-Nimrod , I, Svedholm-Häkkinen, A M , Riekki , T , Kundtová Klocová , E , Ramsay , J E \& Bulbulia , J 2017 , ' Global evidence of extreme intuitive moral prejudice against atheists ' , Nature Human Behaviour , vol. 83 , no. suppl , 0151 . https://doi.org/10.1038/s41562-017-0151

http://hdl.handle.net/10138/246517

https://doi.org/10.1038/s41562-017-0151

publishedVersion

Downloaded from Helda, University of Helsinki institutional repository.

This is an electronic reprint of the original article.

This reprint may differ from the original in pagination and typographic detail.

Please cite the original version. 


\title{
Global evidence of extreme intuitive moral prejudice against atheists
}

\author{
Will M. Gervais ${ }^{1 \star}$, Dimitris Xygalatas ${ }^{2,3}$, Ryan T. McKay ${ }^{4}$, Michiel van Elk ${ }^{5}$,Emma E. Buchtel ${ }^{6}$, \\ Mark Aveyard7, Sarah R. Schiavone', Ilan Dar-Nimrod ${ }^{8}$, Annika M. Svedholm-Häkkinen', \\ Tapani Riekki ${ }^{9}$, Eva Kundtová Klocová ${ }^{10}$, Jonathan E. Ramsay ${ }^{11}$ and Joseph Bulbulia ${ }^{12}$
}

\begin{abstract}
Mounting evidence supports long-standing claims that religions can extend cooperative networks ${ }^{1-9}$. However, religious prosociality may have a strongly parochial component ${ }^{5}$. Moreover, aspects of religion may promote or exacerbate conflict with those outside a given religious group, promoting regional violence ${ }^{10}$, intergroup conflict ${ }^{11}$ and tacit prejudice against non-believers ${ }^{12,13}$. Anti-atheist prejudice-a growing concern in increasingly secular societies ${ }^{14}-$ affects employment, elections, family life and broader social inclu$\operatorname{sion}^{12,13}$. Preliminary work in the United States suggests that anti-atheist prejudice stems, in part, from deeply rooted intuitions about religion's putatively necessary role in morality. However, the cross-cultural prevalence and magnitude-as well as intracultural demographic stability-of such intuitions, as manifested in intuitive associations of immorality with atheists, remain unclear. Here, we quantify moral distrust of atheists by applying well-tested measures in a large global sample ( $N=3,256 ; 13$ diverse countries). Consistent with cultural evolutionary theories of religion and morality, people in most-but not all- of these countries viewed extreme moral violations as representative of atheists. Notably, anti-atheist prejudice was even evident among atheist participants around the world. The results contrast with recent polls that do not find self-reported moral prejudice against atheists in highly secular countries ${ }^{15}$, and imply that the recent rise in secularism in Western countries has not overwritten intuitive anti-atheist prejudice. Entrenched moral suspicion of atheists suggests that religion's powerful influence on moral judgements persists, even among non-believers in secular societies.
\end{abstract}

Speculation about whether morality depends on religious belief has a long history. The ancient Chinese philosopher Mozi claimed that belief in ghosts was essential for moral restraint ${ }^{16}$. In Plato's Euthyphro ${ }^{17}$, Socrates debated whether morality can even be properly defined without reference to divine preference. Dostoevsky ${ }^{18}$ famously questioned whether moral prohibitions could carry weight without belief in a deity. Modern investigations reflect this perceived link between belief in god(s) and morality, as recent small sample studies in North America suggest deep moral suspicion of individuals who do not believe in $\operatorname{god}(\mathrm{s})^{13,19}$.

Evolutionary theories of religion predict that prejudice against atheists may persist even in secular cultures, either as part of a suite of adaptations linking belief to within-group cooperation ${ }^{20}$ or as a consequence of culturally transmitted ${ }^{21}$ and entrenched proreligious norms $s^{5}$. Indeed, recent studies suggest religions evolved in part by supporting trust and cooperation among coreligionists ${ }^{15,22,23}$. Signals of religiosity can even extend trust across religions among believers, though not to non-believers ${ }^{24}$. In contrast, classic social psychological work ${ }^{25}$ predicts that only believers will be prejudiced against atheists and that distrust of atheists would not be apparent in secular societies. To date, these two perspectives have not been directly contrasted, and the global prevalence of intuitive antiatheist prejudice and its persistence among atheists themselves is currently unknown. A recent Pew survey suggests a relationship between country-wide levels of religious belief and explicit judgements that morality requires religion ${ }^{15}$. However, people often lack introspective access to their intuitions, and respond to appear socially desirable. As such, little is known about the potential crosscultural ubiquity of intuitions linking religion and morality.

Here, we rigorously test a prediction derived from a cultural evolutionary model of religion ${ }^{5}$ : that anti-atheist prejudice remains globally prevalent, even in secular societies and among atheists. In contrast to previous studies, we quantify levels of anti-atheist distrust using well-tested measures of intuitive information processing that can be adapted for studying prejudice in a large and diverse cross-cultural sample, while adjusting for individual differences in level of religious belief, demographic covariates and country-level dependencies in responses. Our sample is drawn from 13 countries on 5 continents. We chose these countries because they: (1) exhibit substantial country-level variability in average religious belief including both highly secular societies (for example, Netherlands, Czech Republic, Finland, China) and highly religious ones (for example, United Arab Emirates, Mauritius, India; Supplementary Table 3 shows average belief in god(s) across countries); (2) represent diverse dominant religions and religious histories, including countries with Christian, Muslim, Hindu, Buddhist and secular majorities; and (3) represent diverse cultural, political, socioeconomic, historical and geographical contexts. This diverse sample allowed us to extend our investigation well beyond the WEIRD (Western, educated, industrialized, rich, democratic) samples that predominate the social sciences ${ }^{26}$.

We developed a measure to assess extreme anti-atheist prejudice by using a simple experimental design that targets intuitive biases ${ }^{19}$. In this task, participants read a description of a man who tortures animals as a child then as an adult exhibits escalating violence

'University of Kentucky, Lexington, Kentucky 40506, USA. ${ }^{2}$ University of Connecticut, Storrs, Connecticut 06269, USA. ${ }^{3}$ Aarhus University, Nordre Ringgade 1, 8000 Aarhus, Denmark. ${ }^{4}$ Royal Holloway, University of London, Egham, Surrey, TW20 OEX, UK. ${ }^{5}$ University of Amsterdam, Spui 21, 1012 WX, Amsterdam, Netherlands. ${ }^{6}$ The Education University of Hong Kong, 10 Lo Ping Road, Tai Po, New Territories, Hong Kong. ${ }^{7}$ American University of Sharjah, UAE Code 971 , Sharjah Code 6, United Arab Emirates. ${ }^{8}$ The University of Sydney, Camperdown, NSW 2006, Australia. ${ }^{9}$ University of Helsinki, PO Box 3, Fabianinkatu 33, 00014 Helsinki, Finland. ${ }^{10}$ Masaryk University, Žerotínovo nám. 617/9, 60177 Brno, Czech Republic. "'Singapore University of Social Sciences, 461 Clementi Road, Singapore 599491, Singapore. ${ }^{12}$ Victoria University of Wellington, Kelburn, Wellington 6012, New Zealand. *e-mail: will.gervais@uky.edu 


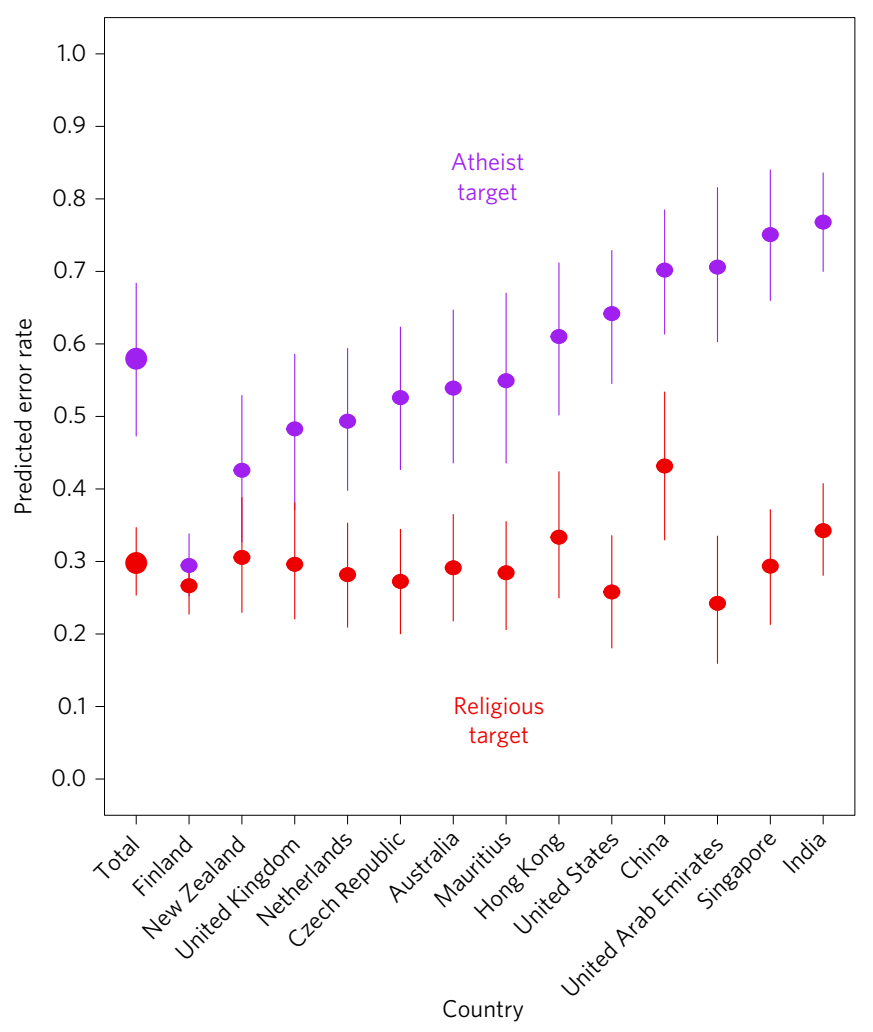

Figure 1 | Across 13 countries, serial murder was seen as more representative of atheists than of religious believers. Predicted error probabilities (95\% HPDI) are presented for the total estimate and all 13 sites.

culminating with the murder and mutilation of five homeless people. Then, participants are judged whether it is more probable that the villain is (A) a teacher or (B) a teacher who either (manipulated between subjects) is a religious believer or does not believe in $\operatorname{god}(\mathrm{s})$. Thus, no individual participant is directly asked whether they think the perpetrator is or is not a believer. Instead, the conjunction fallacy ${ }^{27}$ rates (choosing option $\mathrm{B}$-a logically incorrect answer) between conditions can be used to infer indirectly the degree to which a description of a serial murderer is intuitively seen as more representative of religious people or atheists, respectively. Full stimuli appear in the Supplementary Information. In our preregistration of methods and hypotheses before data collection commenced (https://osf. io/f6tcr/), we hypothesized both universality and variability across countries, such that moral distrust of atheists would be evident in all sites, but the strongest intuitive religion-morality links would be observed in the most strongly religious samples.

We conducted identical experiments in all 13 sites. We targeted at least 100 participants per experimental condition (anti-atheist bias versus anti-religious bias). After filtering out inattentive participants (13\%) and incomplete responses, there were a total of 3,256 participants for final analysis (69\% female, age 16-70 years: mean $=25.07$, s.d. $=7.84$ ), with a median of 162 participants per country (range: 129-993). Participants came from diverse societies and included both student and general population samples (Supplementary Information).

Because our data represent a shared experimental design across sites with participants nested within countries, we used a multilevel (hierarchical) modelling approach. Specifically, our hierarchical Bayesian model ${ }^{28}$ quantifies the extent to which people view gross immorality (animal torture, serial murder and mutilation) as more representative of atheists than of believers, both overall and within each country, adjusting for individual levels of belief in God, gender, age and perceived socioeconomic status (all standardized).
Table 1 | Full model summary.

\begin{tabular}{|c|c|c|c|c|}
\hline \multirow{3}{*}{ 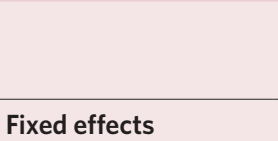 } & \multirow{2}{*}{ Coefficient } & \multirow{2}{*}{ s.d..$_{\text {coef }}$} & \multicolumn{2}{|c|}{ 95\% HPDI } \\
\hline & & & Low & High \\
\hline & \multicolumn{4}{|c|}{ Fixed effects } \\
\hline Belief & 0.10 & 0.06 & -0.03 & 0.23 \\
\hline Age & 0.11 & 0.05 & 0.01 & 0.19 \\
\hline Female & 0.03 & 0.04 & -0.04 & 0.11 \\
\hline SSES & 0.03 & 0.04 & -0.06 & 0.11 \\
\hline Belief $\times$ Target & 0.11 & 0.09 & -0.07 & 0.29 \\
\hline \multicolumn{5}{|l|}{ Random intercepts } \\
\hline Total & -0.86 & 0.12 & -1.09 & -0.63 \\
\hline Australia & -0.90 & 0.19 & -1.27 & -0.51 \\
\hline China & -0.28 & 0.22 & -0.70 & 0.15 \\
\hline Czech Republic & -0.99 & 0.19 & -1.38 & -0.62 \\
\hline Finland & -1.01 & 0.10 & -1.22 & -0.82 \\
\hline Hong Kong & -0.70 & 0.21 & -1.11 & -0.28 \\
\hline India & -0.66 & 0.15 & -0.95 & -0.37 \\
\hline Mauritius & -0.93 & 0.19 & -1.31 & -0.57 \\
\hline Netherlands & -0.94 & 0.18 & -1.30 & -0.57 \\
\hline New Zealand & -0.82 & 0.20 & -1.21 & -0.43 \\
\hline Singapore & -0.90 & 0.21 & -1.31 & -0.50 \\
\hline United Arab Emirates & -1.17 & 0.26 & -1.66 & -0.67 \\
\hline United Kingdom & -0.87 & 0.20 & -1.26 & -0.48 \\
\hline United States & -1.08 & 0.21 & -1.50 & -0.69 \\
\hline \multicolumn{5}{|l|}{ Random slopes (target) } \\
\hline Total & 1.19 & 0.22 & 0.74 & 1.62 \\
\hline Australia & 1.06 & 0.28 & 0.51 & 1.62 \\
\hline China & 1.15 & 0.30 & 0.55 & 1.71 \\
\hline Czech Republic & 1.10 & 0.27 & 0.55 & 1.63 \\
\hline Finland & 0.13 & 0.15 & -0.14 & 0.43 \\
\hline Hong Kong & 1.16 & 0.31 & 0.56 & 1.75 \\
\hline India & 1.87 & 0.23 & 1.44 & 2.35 \\
\hline Mauritius & 1.13 & 0.29 & 0.57 & 1.72 \\
\hline Netherlands & 0.91 & 0.26 & 0.39 & 1.42 \\
\hline New Zealand & 0.52 & 0.29 & -0.06 & 1.08 \\
\hline Singapore & 2.02 & 0.32 & 1.41 & 2.65 \\
\hline United Arab Emirates & 2.06 & 0.36 & 1.35 & 2.76 \\
\hline United Kingdom & 0.80 & 0.29 & 0.21 & 1.34 \\
\hline United States & 1.66 & 0.29 & 1.13 & 2.24 \\
\hline
\end{tabular}

Age, gender, subjective socioeconomic status (SSES) and participant belief in God were standardized. Target was coded: atheist $=1$, religious $=0$. The $95 \%$ HPDI illustrates uncertainty around posterior means, and indexes the interval in which the $95 \%$ most credible estimates lie.

Additionally, the model adjusts for country-level dependencies by modelling the intercept and slope of anti-atheist prejudice as random across countries (Supplementary Information). Full model coefficients appear in Table 1 . We observed substantial heterogeneity in overall conjunction fallacy performance across countries. Because our primary focus was on degrees of intuitive moral distrust of atheists (in contrast to believers) across countries, we do not speculate further about sources of heterogeneity in overall performance, and instead focus on experimental condition differences within countries.

Our results offer strong evidence of extreme intuitive moral prejudice against atheists. Our model predicts an overall conjunction error rate probability of 0.58 for atheist targets (95\% highest posterior density interval (HPDI) $0.48,0.68)$, but only 0.30 (95\% 
HPDI $0.25,0.34)$ for religious targets; relative risk is 1.96 (95\% HPDI 1.53, 2.37) (posterior probability of atheist target errors exceeding religious target errors (henceforth 'posterior probability') exceeds 0.999 ). Thus, people overall are roughly twice as likely to view extreme immorality as representative of atheists, relative to believers. Importantly, the effects hold even after adjusting for country variability in the strength of intuitive moral prejudice and individual-level variability in demographics. Figure 1 and Table 2 summarize model-predicted conjunction error probabilities across sites for atheist and religious targets. Consistent with predictions, extreme intuitive moral distrust of atheists is both globally evident and variable in its magnitude across countries.

Surprisingly, after adjusting for substantial latent country-level dependencies between sites, the within-country interaction between individual belief in God and conjunction error rates across targets is weak (posterior probability $=0.88$; Table 1 ). Thus, while anti-atheist prejudice varies strongly by country, such prejudice is largely robust across the spectrum of participant religiosity within countries; both high and low believers are about twice as likely to commit conjunction errors for atheist targets than for religious targets (Fig. 2). Furthermore, we examined posterior model predictions for atheists (those rating their belief in God at 0 out of 100). Among atheists, our model predicts an overall conjunction error rate probability of 0.52 for atheist targets (95\% HPDI 0.40, 0.64), but only 0.28 (95\% HPDI $0.22,0.33$ ) for religious targets; relative risk is 1.91 (95\% HPDI 1.41, 2.48 ) (posterior probability $>0.999$ ). Effects hold even in highly secular countries such as Australia, China, the Czech Republic, the Netherlands and the United Kingdom: even atheists are predicted to intuitively associate serial murder more with atheists than with believers in these countries (all posterior probabilities exceeding 0.98 ). Indeed, only in Finland (posterior probability $=0.48$ ) and to a lesser extent New Zealand (posterior probability $=0.90$ ) is the evidence of intuitive anti-atheist prejudice among atheists less conclusive. (Full inferences at both minimum and maximum belief appear in the Supplementary Information.) To check robustness of intuitive moral distrust of atheists among atheists, we conducted a second analysis isolating all participants across sites who rated their belief in God at zero $(N=553)$ and explored overall atheist intuitive moral distrust of atheists (experimental condition treated as fixed) across sites (varying intercepts of country). Again, atheist participants showed higher conjunction error rates for atheist targets, 0.61 (95\% HPDI $0.23,0.95$ ), than for religious targets, 0.50 (95\% HPDI 0.12 , 0.88 ) (posterior probability $=0.999$ ). Thus, consistent with theoretical predictions, even atheists intuitively associate immorality more with atheists than with believers.

To address potential methodological confounds and alternative explanations for our findings, we conducted three additional experiments (note that, although our primary cross-cultural investigation was preregistered, the follow-up studies were not). Full details of all three studies appear in the Supplementary Information, but they are briefly summarized here. First, our cross-cultural experimental manipulation tested only extreme moral violations and pitted a target who 'does not believe in god(s)' against a 'religious believer', perhaps confounding notions of belief in $\operatorname{god}(s)$ and the broader construct of religiosity. Supplementary Study S1 found that, even when the experiment more symmetrically manipulates belief versus disbelief in $\operatorname{god}(\mathrm{s})$ and tests a more minor moral violation (for example, not paying for dinner in a restaurant), people still associate immorality more with atheists than with believers (posterior probability $=0.981)$.

Second, our primary cross-cultural tests pitted a disbeliever in $\operatorname{god}(\mathrm{s})$ against a religious believer. It is possible, however, that people are morally distrustful of disbelievers in general, rather than of people who disbelieve in $\operatorname{god}(\mathrm{s})$ specifically. Supplementary Study S2 used the same extreme moral violation as our main analysis and found that people are more likely to assume intuitively that a

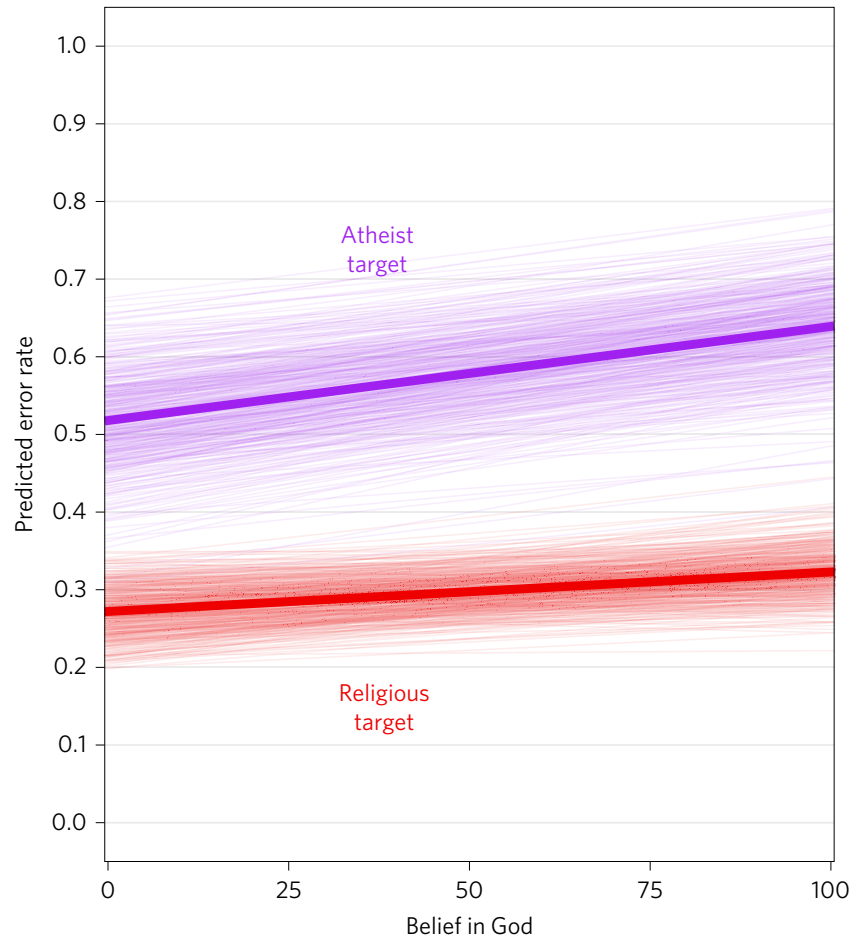

Figure 2 | Predicted effect of participant belief in God, marginalized across countries and adjusting for individual gender, age and subjective socioeconomic status. Bold lines are overall estimates. Blurred lines display 500 best-fit lines sampled randomly from the posterior to depict estimate uncertainty.

perpetrator of moral evil is someone who disbelieves in God than someone who disbelieves in evolution, the accuracy of horoscopes, the safety of vaccines or the reality of global warming (all posterior probabilities between 0.956 and 0.9997).

Finally, it is possible that people may intuitively associate certain specific moral violations, such as child molestation, with religious individuals rather than with atheists. However, Supplementary Study S3 found that people intuitively assume that a priest who molests young boys for decades is more likely to be a priest who does not believe in God than a priest who does believe in God (posterior probability $=0.998$ ).

In summary, participants intuitively assume that the perpetrators of immoral acts are probably atheists. These effects appeared across religiously diverse societies, including countries with Buddhist, Christian, Hindu, Muslim and non-religious majorities, showing that intuitive moral prejudice against atheists is not exclusive to Abrahamic or monotheistic majority societies. To the contrary, intuitive anti-atheist prejudice generalizes to largely secular societies and appears globally evident even among atheists. Notably, our primary experimental paradigm used extreme examples of immorality where anti-atheist prejudice would presumably be less explicitly defensible. We tested moral prejudice using vicious acts of cruelty (animal torture, serial murder and mutilation), which participants-including atheist participants-nonetheless intuitively associated with atheists. Combined, these results show that across the world, religious belief is intuitively viewed as a necessary safeguard against the temptations of grossly immoral conduct, and atheists are broadly perceived as potentially morally depraved and dangerous. Viewed differently, people perceive belief in a god as a sufficient moral buffer to inhibit immoral behaviour.

Our results highlight a stark divergence between lay and scientific perceptions of the relationship between religion and morality. Although religion probably influences many moral outcomes and 
Table 2 | Model summary of mean belief in God (50.91 out of 100).

\begin{tabular}{|c|c|c|c|c|c|}
\hline & $N$ & Atheist & Religious & Relative risk & $\operatorname{Pr}(A>R)$ \\
\hline Total & 3,256 & $0.58(0.48,0.68)$ & $0.30(0.25,0.34)$ & $1.96(1.53,2.37)$ & $>0.999$ \\
\hline Australia & 158 & $0.54(0.43,0.65)$ & $0.29(0.22,0.37)$ & $1.89(1.33,2.55)$ & $>0.999$ \\
\hline Czech Republic & 187 & $0.53(0.43,0.62)$ & $0.27(0.20,0.34)$ & $1.97(1.37,2.66)$ & $>0.999$ \\
\hline Finland & 993 & $0.29(0.25,0.34)$ & $0.27(0.23,0.31)$ & $1.11(0.89,1.34)$ & 0.822 \\
\hline Hong Kong & 129 & $0.61(0.50,0.71)$ & $0.33(0.25,0.43)$ & $1.87(1.30,2.48)$ & $>0.999$ \\
\hline Mauritius & 161 & $0.55(0.43,0.67)$ & $0.28(0.21,0.36)$ & $1.96(1.36,2.64)$ & $>0.999$ \\
\hline Netherlands & 213 & $0.49(0.40,0.59)$ & $0.28(0.21,0.35)$ & $1.77(1.23,2.34)$ & 0.999 \\
\hline New Zealand & 161 & $0.43(0.33,0.53)$ & $0.31(0.23,0.39)$ & $1.41(0.92,1.92)$ & 0.964 \\
\hline Singapore & 162 & $0.75(0.66,0.84)$ & $0.29(0.21,0.37)$ & $2.63(1.84,3.47)$ & $>0.999$ \\
\hline United Arab Emirates & 144 & $0.71(0.60,0.81)$ & $0.24(0.15,0.32)$ & $3.06(1.95,4.39)$ & $>0.999$ \\
\hline
\end{tabular}

Predicted conjunction error probabilities for both atheist and religious targets (95\% HPDIs in parentheses), along with relative risks ( $95 \% \mathrm{HPDI}$ in parentheses) and posterior probability of atheist target error rates $(A)$ exceeding religious target error rates $(R)(\operatorname{Pr}(A>R))$. Relative risk $=\operatorname{Pr}($ atheist target error)/ $\operatorname{Pr}($ religious target error)

judgements ${ }^{3,22,23}$, core moral instincts appear to emerge largely independent of religion ${ }^{29,30}$. Additionally, highly secular societies are among the most stable and cooperative on Earth ${ }^{14}$. Nonetheless, our findings reveal widespread suspicion that morality requires belief in a god. For many people, including many atheists, the answer to Dostoevsky's ${ }^{18}$ question "Without God ... It means everything is permitted now, one can do anything?" is "Yes", inasmuch as 'everything' refers to acts of extreme immorality.

Religions underpin large-scale intragroup cooperation ${ }^{3}$, but they also promote distrust of non-believers ${ }^{13,19}$ who are excluded from such religious moral communities ${ }^{3,24}$. Does rising secularism ${ }^{14,31}$ moderate effects as atheist norms become stronger within societies? The present findings suggest that intuitive moral suspicion of atheists is culturally widespread, though not universal. Given that intuitive anti-atheist biases may transfer across moral domains ${ }^{19}$ (Supplementary Studies S1 and S3), the resilience of moral prejudice against atheists reveals a potential barrier to the full acceptance of this growing segment ${ }^{31}$ of the global population. Consistent with predictions derived from cultural evolutionary theories of religion and morality ${ }^{5}$, extreme intuitive moral distrust of atheists is evident globally, among believers and atheists in both religious and secular societies. Even as secularism reduces overt religiosity in many places $^{14}$, religion has apparently still left a deep and abiding mark on human moral intuitions.

\section{Methods}

Data collection proceeded among teams acting locally across all 13 countries. Local ethics approval was completed by individual research teams within each country.

The experiment used a version of the representativeness heuristic ${ }^{27}$. In the classic version of this task, participants are given a description of a politically liberal single woman. When asked whether it is more likely that she is (A) a bank cashier or (B) a bank cashier who is active in the feminist movement, participants tend erroneously to pick option B. Although logically incorrect (there are necessarily at least as many bank cashiers as bank cashiers who are feminists), the description seems more representative of the double identity provided in option B, leading people intuitively to choose that option (termed 'the conjunction fallacy'). By independently varying the contents of the description and the identities implied by option $B$, researchers can assess the degree to which people intuitively view a given description as representative of different identities ${ }^{19}$.

We generated a representativeness heuristic task to quantify the degree to which people around the world intuitively view religion as necessary for the inhibition of grossly immoral behaviour. We provided a description of an immoral person who initially tortures animals and eventually kills people for thrills (see Supplementary Information), and then asked whether it was more probable that the perpetrator was (A) a teacher or (B) a teacher who either (manipulated between subjects) does not believe in God or is a religious believer. Higher conjunction fallacy rates (picking option B) in the atheist condition indicate that people intuitively view serial murder as more representative of atheists than of religious believers ${ }^{19}$. This manipulation allowed us to test the relationship between intuitive distrust of atheists and personal religious belief, while adjusting for country-wide variation in this relationship, as well as demographic covariates.

Analytic strategy. The nested structure of our data required a multilevel (hierarchical) modelling strategy to generate aggregate inferences. Failure to adopt such a strategy can lead to serious and potentially misleading inferential errors $^{32}$. Our analyses relied on Bayesian hierarchical modelling ${ }^{28}$ using the rethinking package ${ }^{33}$ in R. Bayesian approaches provide researchers with a number of pragmatic benefits ${ }^{34}$, including the use of intuitive statements (posterior probabilities) about the probability of experimental manipulations producing effects across countries, as well as the relative credibility or plausibility of different potential parameter values ${ }^{28,35}$. In addition, hierarchical (multilevel) models can mitigate some problems associated with multiple comparison $s^{36}$ - comparisons that could be especially concerning in the present study, which evaluated intuitive moral distrust of atheists across 13 countries while adjusting for individual demographics. Furthermore, Bayesian estimation allowed us to represent the estimate uncertainty using HPDIs, which represent the range in which the most credible parameter values lie. This approach is in contrast to frequentist confidence intervals, which present only a range of possible values that would contain the true parameter value a known proportion of the time were this study repeated a very large number of times, although frequentist confidence intervals are often intuitively misunderstood as if they had the properties of Bayesian posterior density intervals ${ }^{37}$. Our primary inferences are drawn from probing samples from the posterior from a single hierarchical model. In it, we modelled random intercepts of country and modelled effects of target (atheist versus believer) as random across country, with all other factors fixed across country. Alternative model specifications did not appreciably change inferences.

Data availability. Data and code are freely available at https://osf.io/f0upy/

Received 14 June 2016; accepted 23 June 2017; published 7 August 2017

\section{References}

1. Atkinson, Q. D. \& Bourrat, P. Beliefs about God, the afterlife and morality support the role of supernatural policing in human cooperation. Evol. Hum Behav. 32, 41-49 (2011).

2. Purzycki, B. G. et al. Moralistic gods, supernatural punishment and the expansion of human sociality. Nature 530, 327-330 (2016).

3. Graham, J. \& Haidt, J. Beyond beliefs: religions bind individuals into moral communities. Pers. Soc. Psychol. Rev. 14, 140-150 (2010).

4. Sosis, R. \& Alcorta, C. Signaling, solidarity, and the sacred: the evolution of religious behavior. Evol. Anthropol. 12, 264-274 (2003).

5. Norenzayan, A. et al. The cultural evolution of prosocial religions. Behav. Brain Sci. http://dx.doi.org/10.1017/S0140525X14001356 (2016). 
6. Xygalatas, D. et al. Extreme rituals promote prosociality. Psychol. Sci. 24, 1602-1605 (2013).

7. Turchin, P. War and Peace and War: The Life Cycles of Imperial Nations $(\mathrm{Pi}, 2005)$.

8. Botero, C. A. et al. The ecology of religious beliefs. Proc. Natl Acad. Sci. USA 111, 16784-16789 (2014).

9. Baumard, N. \& Boyer, P. Explaining moral religions. Trends Cogn. Sci. 17, 272-280 (2013).

10. Atran, S. \& Ginges, J. Religious and sacred imperatives in human conflict. Science 336, 855-857 (2012).

11. Neuberg, S. L. et al. Religion and intergroup conflict findings from the Global Group Relations Project. Psychol. Sci. 25, 198-206 (2014).

12. Edgell, P., Gerteis, J. \& Hartmann, D. Atheists as "other": moral boundaries and cultural membership in American society. Am. Sociol. Rev. 71, 211-234 (2006).

13. Gervais, W. M., Shariff, A. F. \& Norenzayan, A. Do you believe in atheists? Distrust is central to anti-atheist prejudice. J. Pers. Soc. Psychol. 101, 1189-1206 (2011).

14. Inglehart, R. \& Norris, P. Sacred and Secular: Religion and Politics Worldwide (Cambridge Univ. Press, 2004).

15. Worldwide, Many See Belief in God as Essential to Morality (Pew Research Center, 2014).

16. Johnston, I. The Mozi: A Complete Translation (Columbia Univ. Press, 2010).

17. Plato. Euthyphro (Internet Classics Archive); http://classics.mit.edu/Plato/euthyfro.html

18. Dostoevsky, F. The Brothers Karamazov 12th edn (Farrar, Straus \& Giroux, 2002).

19. Gervais, W. M. Everything is permitted? People intuitively judge immorality as representative of atheists. PLoS ONE 9, e92302 (2014).

20. Johnson, D. \& Bering, J. Hand of God, mind of man: punishment and cognition in the evolution of cooperation. Evol. Psychol. 4, 219-233 (2006).

21. Boyd, R., Richerson, P. J. \& Henrich, J. The cultural niche: why social learning is essential for human adaptation. Proc. Natl Acad. Sci USA 108, 10918-10925 (2011).

22. McKay, R. \& Whitehouse, H. Religion and morality. Psychol. Bull. 141, 219-233 (2015).

23. Bloom, P. Religion, morality, evolution. Annu. Rev. Psychol. 63, 179-199 (2012).

24. Hall, D. L., Cohen, A. B., Meyer, K. K., Varley, A. H. \& Brewer, G. A. Costly signaling increases trust, even across religious affiliations. Psychol. Sci. 26, 1368-1376 (2015).

25. Tajfel, H. \& Turner, J. C. in The Social Psychology of Intergroup Relations (eds Austin, W. G. \& Worchel, S.), 33-47 (Brooks/Cole, 1979).

26. Henrich, J., Heine, S. J. \& Norenzayan, A. The weirdest people in the world? Behav. Brain Sci. 33, 61-83 (2010).

27. Tversky, A. \& Kahneman, D. Extensional versus intuitive reasoning-the conjunction fallacy in probability judgment. Psychol. Rev. 90, 293-315 (1983).

28. McElreath, R. Statistical Rethinking: A Bayesian Course with Examples in $R$ and Stan Vol. 122 (CRC Press, 2016)

29. Hamlin, J. K., Wynn, K. \& Bloom, P. Social evaluation by preverbal infants. Nature 450, 557-559 (2007).
30. De Waal, F. B. The antiquity of empathy. Science 336, 874-876 (2012)

31. Gervais, W. M. \& Najle, M. B. How many atheists are there? Soc. Psychol Personal. Sci. Preprint at https://osf.io/preprints/psyarxiv/edzda (2017).

32. Shariff, A. F., Willard, A. K., Muthukrishna, M., Kramer, S. R. \& Henrich, J. What is the association between religious affiliation and children's altruism? Curr. Biol. 26, R699-R700 (2016)

33. rethinking: Statistical Rethinking Book Package. R package v.1.58 (Richard McElreath, 2015).

34. Wagenmakers, E.-J., Morey, R. D. \& Lee, M. D. Bayesian benefits for the pragmatic researcher. Curr. Dir. Psychol. Sci. 25, 169-176 (2016).

35. Kruschke, J. K. Doing Bayesian Data Analysis: A Tutorial Introduction with $R$ (Academic Press, 2010)

36. Gelman, A., Hill, J. \& Yajima, M. Why we (usually) don't have to worry about multiple comparisons. J. Res. Educ. Eff. 5, 189-211 (2012).

37. Hoekstra, R., Morey, R. D., Rouder, J. N. \& Wagenmakers, E.-J. Robust misinterpretation of confidence intervals. Psychon. B. Rev. 21, 1157-1164 (2014).

\section{Acknowledgements}

This research was supported by a grant to W.M.G. from the John Templeton Foundation (48275). J.B. was supported by grants from the Templeton World Charity Foundation (0077) and a Royal Society of New Zealand Marsden Grant (VUW1321). D.X. acknowledges support from the Interacting Minds Centre at Aarhus University. R.T.M. acknowledges the support of the John Templeton Foundation (52257) and the ARC Centre of Excellence in Cognition and its Disorders at Macquarie University. M.v.E. acknowledges support by a Veni grant (016.135.135) from the Netherlands Organisation for Scientific Research. The content is solely the responsibility of the authors and does not necessarily represent the official views of its funders. The funders had no role in study design, data collection and analysis, decision to publish or preparation of the manuscript.

\section{Author contributions}

W.M.G. developed the study design in consultation with all the authors. W.M.G. and J.B. performed the analyses. W.M.G., D.X., M.v.E., J.B. and R.T.M. wrote the manuscript with input from all authors. All authors were involved in data collection.

\section{Additional information}

Supplementary information is available for this paper.

Reprints and permissions information is available at www.nature.com/reprints.

Correspondence and requests for materials should be addressed to W.M.G.

How to cite this article: Gervais, W. M. et al. Global evidence of extreme intuitive moral prejudice against atheists. Nat. Hum. Behav. 1, 0151 (2017).

Publisher's note: Springer Nature remains neutral with regard to jurisdictional claims in published maps and institutional affiliations.

\section{Competing interests}

The authors declare no competing interests. 